\title{
Integrity of cortical perineuronal nets influences corticospinal tract plasticity after spinal cord injury
}

\author{
C. Orlando • O. Raineteau
}

Received: 23 July 2013/ Accepted: 26 December 2013/Published online: 31 January 2014

(C) The Author(s) 2014. This article is published with open access at Springerlink.com

\begin{abstract}
The rapid decline of injury-induced neuronal circuit remodelling after birth is paralleled by the accumulation of chondroitin sulphate proteoglycans (CSPGs) in the extracellular matrix, culminating with the appearance of perineuronal nets (PNNs) around parvalbumin-expressing GABAergic interneurons. We used a spinal cord injury (SCI) model to study the interplay between integrity of PNN CSPGs in the sensorimotor cortex, anatomical remodelling of the corticospinal tract (CST) and motor recovery in adult mice. We showed that thoracic SCI resulted in an atrophy of GABAergic interneurons in the axotomized hindlimb cortex, as well as in a more widespread downregulation of parvalbumin expression. In parallel, spontaneous changes in the integrity of CSPG glycosaminoglycan (GAG) chains associated with PNNs occurred at the boundary between motor forelimb and sensorimotor hindlimb cortex, a region previously showed to undergo reorganization after thoracic SCI. Surprisingly, full digestion of CSPG GAG chains by intracortical chondroitinase $A B C$ injection resulted in an aggravation of motor deficits and reduced sprouting of the axotomized CST above the lesion. Altogether, our data show that changes in the expression pattern of GABAergic markers and PNNs occur in regions of the sensorimotor cortex undergoing
\end{abstract}

Electronic supplementary material The online version of this article (doi:10.1007/s00429-013-0701-9) contains supplementary material, which is available to authorized users.

\footnotetext{
C. Orlando · O. Raineteau $(\bowtie)$

Brain Research Institute, University of Zurich/ETH,

Winterthurerstrasse 190, 8057 Zurich, Switzerland

e-mail: raineteau@hifo.uzh.ch

C. Orlando

e-mail: orlando@hifo.uzh.ch
}

spontaneous reorganization after SCI, but suggest that these changes have to be tightly controlled to be of functional benefit.

Keywords Extracellular matrix - Chondroitin sulphate proteoglycans - Chondroitinase · Parvalbumin · Plasticity

\section{Introduction}

An incomplete spinal cord injury (SCI) is followed by spontaneous anatomical and functional reorganization of motor circuits at multiple levels of the neuraxis (Oudega and Perez 2012; Raineteau and Schwab 2001). After a thoracic lesion, axotomized hindlimb corticospinal neurons located at the boundary between motor forelimb $(\mathrm{mFL})$ and sensorimotor hindlimb (smHL) cortical areas are functionally incorporated into the sensorimotor circuits of the unaffected forelimb (Fouad et al. 2001; Ghosh et al. 2009, 2010). In parallel, sprouting of axotomized corticospinal fibres occurs in the spinal cord, both rostrally and caudally to the site of injury (Fouad et al. 2001; Weidner et al. 2001; Ghosh et al. 2009; Courtine et al. 2008), leading to the formation of new functional circuits and the partial re-establishment of supraspinal motor control (Bareyre et al. 2004; Fouad et al. 2001; Ghosh et al. 2010). These compensatory responses are however limited and not sufficient to support complete functional recovery. Chondroitin sulphate proteoglycans (CSPGs), perineuronal nets (PNNs) and parvalbumin-expressing $(\mathrm{PV}+)$ interneurons are some of the main factors which limit experience-dependent remodelling of adult neuronal circuits. CSPGs are the main components of the mature extracellular matrix (ECM) where they are diffusely expressed or aggregated 
as PNNs mainly around PV+ interneurons. In the cortex, PNN appearance regulates the maturation of PV inhibitory circuits and correlates with the gradual closure of the critical period for plasticity (Pizzorusso et al. 2002; Sale et al. 2007; Makara et al. 2007; Beurdeley et al. 2012; Dityatev et al. 2007). Chondroitinase ABC (ChABC)-mediated digestion of CSPGs and PNNs in animal model of SCI promotes axonal regeneration at the site of injury (Bradbury et al. 2002; Carter et al. 2008; Chau et al. 2004; Moon et al. 2001; Cafferty et al. 2007) and enhances functional sprouting of both intact and injured pathways rostral and caudal to the lesion site (Barritt et al. 2006; Cafferty et al. 2008; Massey et al. 2006; Starkey et al. 2012; Tom et al. 2009; Bradbury et al. 2002; Caggiano et al. 2005; Fouad et al. 2005; Tester and Howland 2008). In the adult visual cortex, ChABC-mediated PNN digestion restores ocular dominance plasticity (Pizzorusso et al. 2002). In the same system, pharmacological reduction of GABAergic transmission leads to a decrease in the expression of cortical PNNs and reactivation of ocular dominance plasticity (Harauzov et al. 2010). In animal models of stroke, spontaneous downregulation of PNN expression occurs in cortical area (i.e. peri-infarct and remote areas) known to undergo compensatory remodelling of neuronal networks (Bidmon et al. 1998; Hobohm et al. 2005). Thus, CSPGs, PNNs and PV+ cells act in concert to restrict anatomical and functional plasticity of the injured adult CNS.

In this study, we investigated the consequences of a thoracic SCI on the expression of GABAergic markers and PNN CSPGs across the mouse sensory and motor cortical areas which are known to undergo sustained reorganization after SCI (Ghosh et al. 2009, 2010). We showed that SCI induced a localized and layer-specific modulation of the cortical inhibitory system and led to changes in the integrity of PNN CSPGs at the boundary between the motor forelimb $(\mathrm{mFL})$ and the sensorimotor hindlimb (smHL) cortical areas. Intracortical injection of ChABC to further digest CSPG GAG chains did however not promote functional recovery. Contrariwise, it prevented spontaneous sprouting of the axotomized CST neurons in the cervical spinal cord and resulted in a transient, limb-specific aggravation of motor deficits, suggesting that these cortical changes must be tightly controlled to be of functional benefit.

\section{Methods}

C57BL/6 and GAD67-GFP female mice (mean age 2.5 months, $n=54$ ) were used in this study. All surgical procedures and experimental manipulations were performed in agreement with Canton of Zurich Veterinary Office guidelines.

\section{Experimental design}

Mice were divided into seven experimental groups as indicated in Table 1. Heterozygous knock-in mice expressing an enhanced green fluorescent protein (EGFP) under the glutamic decarboxylase GAD67 genomic regulatory sequences (i.e. GAD67 $7^{+/ E G F P}$ mice) were used in groups 1 and 2 to study the effects of thoracic SCI on the expression of cortical GABAergic markers and PNNs. In this knock-in mouse line, $95 \%$ of GABAergic cells express GFP in a spatially and temporally regulated manner (Tamamaki et al. 2003). These animals were euthanized 2 weeks after SCI. Wild-type C57BL/6 mice were used in groups 3-7. Mice of group 3 were euthanized at 2, 7 and 14 days after cortical injection of ChABC to estimate the diffusion of the enzyme. Mice of groups 4-7 were used to address the extent of locomotor recovery after SCI and the role of cortical CSPG GAG chains digestion on the spontaneous cervical sprouting of axotomized hindlimb corticospinal neurons. Mice received a cortical injection of ChABC (groups 5 and 7) or of the control enzyme penicillinase (Pase; groups 4 and 6). Groups 6 and 7 underwent in addition a dorsal thoracic hemisection. All mice were tested for locomotor recovery ability and received an anterograde tracer injection at 28 days post-injury (dpi) to trace their CST. All mice from groups 4-7 were euthanized 6 weeks after injury.

\section{Surgical procedures}

Mice were anaesthetized using a combination of Hypnorm (fentanyl-citrate $0.7 \mathrm{mg} / \mathrm{kg}$, fluanisone $22.5 \mathrm{mg} / \mathrm{kg}$, Janssen Pharmaceutics) and Dormicum (midazolam $22.5 \mathrm{mg} / \mathrm{kg}$, Roche Pharmaceuticals) administered via intraperitoneal injection.

Groups 4-7 underwent cortical injection of Pase or ChABC prior to SCI (details in Table 1). Mice were secured in a stereotaxic frame. A midline incision of the skin was performed and the location of the sensorimotor hindlimb cortex (smHL) was determined relative to Bregma. $1 \mu \mathrm{l}$ of enzymatic solution was injected using a 33-gauge Hamilton syringe (1.25 mediolateral; -0.96 rostrocaudal; 0.6 dorsoventral). After injection, the needle remained in position for 2 min before removal to prevent spillage of the enzymatic solution.

In groups 2, 6 and 7, a dorsal bilateral laminectomy was performed at thoracic level 8 (T8) to expose the dura, and a bilateral dorsal spinal cord hemisection was performed using sharp iridectomy scissors. In 3 mice of group 2, a 
Table 1 Experimental groups

\begin{tabular}{|c|c|c|c|c|c|}
\hline & Strain & Enzymatic treatment & Injury & Motor test & Tracing \\
\hline Group $1(n=4)$ & GAD67 $7^{+/ E G F P}$ & n.p. & n.p. & n.p. & n.p. \\
\hline Group $2(n=7)$ & GAD $67^{+/ \text {EGFP }}$ & n.p. & $\mathrm{T} 8$ & n.p. & Retrograde DY \\
\hline Group $3(n=12)$ & $\mathrm{C} 57 \mathrm{BL} / 6$ & ChABC/vehicle & n.p. & n.p. & n.p. \\
\hline Group $4(n=6)$ & $\mathrm{C} 57 \mathrm{BL} / 6$ & Pase & n.p. & BMS/grid & Anterograde BDA \\
\hline Group $5(n=7)$ & C57BL/6 & $\mathrm{ChABC}$ & n.p. & BMS/grid & Anterograde BDA \\
\hline Group $6(n=9)$ & C57BL/6 & Pase & $\mathrm{T} 8$ & BMS/grid & Anterograde BDA \\
\hline Group $7(n=9)$ & C57BL/6 & ChABC & $\mathrm{T} 8$ & BMS/grid & Anterograde BDA \\
\hline
\end{tabular}

n.p. not performed, ChABC chondroitinase, Pase penicillinase, $T 8$ thoracic level 8, BMS Basso Mouse Scale score, grid horizontal grid test, $D Y$ diamidine yellow, $B D A$ biotinylated dextran amine

retrograde tracer was applied to the injury site as described below.

Following surgery, all animals were kept on a heating plate $\left(36^{\circ} \mathrm{C}\right)$ until fully awake. An analgesic $(5 \mathrm{mg} / \mathrm{kg}$ body weight per subcutaneous injection of Rimadyl; Pfizer) and an antibiotic ( $5 \mathrm{mg} / \mathrm{kg}$ body weight intraperitoneal injection of Baytril; Bayer) were administered once per day for 3 days. Bladders were checked and emptied three times per day until their function had completely recovered.

\section{Tracing of the CST}

Retrograde tracing (mapping of the axotomized smHL area): at the time of axonal injury, $1 \mu$ of the retrograde tracer Diamidine Yellow (DY, $1 \%$; suspension in phosphate buffer (PB) $0.1 \mathrm{M}$ and $2 \%$ dimethyl sulphoxide, EMS-Polyloy, Gross-Umstadt, Germany) was applied at the lesion site with a 33-gauge Hamilton syringe mounted on the stereotaxic frame in 3 mice of group 2. The suspension was left on the transected surface for $15 \mathrm{~min}$.

Anterograde tracing: 4 weeks after surgery, the CST of mice of groups 4-7 was anterogradely traced from the smHL ipsilateral to the treated cortex. Mice were anaesthetized as indicated above and secured in a stereotaxic frame. A midline incision of the skin was performed and the location of the smHL was determined by measuring positions on the skull relative to Bregma. 1- $\mu$ l of biotinylated dextran amine (BDA) solution (10,000 MW, $10 \%$ in PB 0.1 M, Molecular Probes) was injected in the smHL cortical area using a 33-gauge Hamilton syringe.

\section{Enzymatic treatment}

To digest cortical CSPG GAG chains, protease-free chondroitinase ABC (ChABC) from Proteus vulgaris (Seikagaku) was reconstituted in sterile PB $0.1 \mathrm{M}$ (0.1 U/ $\mu \mathrm{l}, \mathrm{pH} 7.4)$ and $1 \mu \mathrm{l}$ was injected in the hindlimb area as indicated above. ChABC digests the GAG chains from the protein core of CSPGs that are diffusely expressed in the ECM or aggregated as PNNs. Pase (matched for protein content in PB $0.1 \mathrm{M}$, Sigma) was used as a control enzyme. To assess the area of enzymatic digestion, 4 mice per time point were euthanized at 2, 7 and 14 days after injection of $\mathrm{ChABC}$, and brain coronal sections were stained with the lectin Wisteria floribunda Agglutinin (WFA) to visualize spared PNNs (see below for detailed staining protocol).

\section{Motor tests}

For evaluation of over-ground locomotion and recovery of motor functions the Basso Mouse Scale (BMS) score was used (Basso et al. 2006). Mice were evaluated at day -1 and 3, 7, 14, 21 and $28 \mathrm{dpi}$. Mice were observed while walking in an open field $(60 \times 43 \mathrm{~cm})$ by an experimenter blinded to the treatment groups and a score from 0 to 9 was assigned based on the following parameters: ankle movement, plantar placing, weight support, stepping, coordination, paw position, trunk stability. Prior to injury, groups 4-7 were trained for 3 days to walk on a horizontal grid. The horizontal grid $(58 \mathrm{~cm}$ long $\times 20 \mathrm{~cm}$ width, $35 \mathrm{~cm}$ elevation) consisted of equally spaced rungs (at $1.2 \mathrm{~cm}$ intervals). Each mouse was allowed to walk on the grid for $3 \mathrm{~min}$ for 3 consecutive times, resting $25 \mathrm{~min}$ between each trial. On the third training day $(-1$ day), the three trials were video recorded to establish a baseline. Mice were further tested and videotaped at 3, 7, 14, 21 and 28 dpi. Videos were analysed offline. When the paw was placed such that the limb did not slip from the rung (correct weight-supported steps), a step was noted as successful. The percentage of footfalls was measured as the number of errors in foot placement out of the total number of steps during the 3-min recording or till a maximum of 50 steps per side. The percentage for each animal was determined by averaging over the first two trials. The right and left paws were analysed separately. 
Tissue processing

Mice were euthanized with an overdose of pentobarbital and transcardially perfused with Ringer (Fresenius Kabi, DE) supplemented with $\mathrm{NaNO}_{2}(40 \mathrm{mM}), \mathrm{NaCHO}_{3}$ $(2 \mathrm{mM})$ and heparin $(50 \mathrm{IE} / \mathrm{ml}, \mathrm{B}$. Braun Medical AG), followed by ice-cold $4 \%$ paraformaldehyde in PB $0.1 \mathrm{M}$. The brains and spinal cords were dissected and post-fixed overnight at $4{ }^{\circ} \mathrm{C}$ in the same fixative. Brains were cryoprotected in a solution of $30 \%$ sucrose in PB $0.1 \mathrm{M}$. Coronal sections $(40 \mu \mathrm{m})$ were cut with a freezing microtome and serially collected as free-floating sections in PB $0.1 \mathrm{M}$. For PV and PNN staining, a complete series of sections (i.e. 12 sections taken at $240 \mu \mathrm{m}$ intervals, spanning $\sim 2.5 \mathrm{~mm}$ of tissue) was permeabilized and blocked in PB $0.1 \mathrm{M}$ supplemented with $0.4 \%$ triton-X100 (PB-TX $0.1 \mathrm{M})$ and $10 \%$ inactivated normal horse serum for $2 \mathrm{~h}$ at room temperature. Sections were incubated with primary antibody/lectin (biotinylated Wisteria floribunda agglutinin (WFA), which labels the GAG chains of CSPGs in the ECM and PNNs, 1:500, B-1355 Vector Lab; mouse monoclonal anti-calcium-binding protein parvalbumin, 1:5000, PV235 Swant) at $4{ }^{\circ} \mathrm{C}$ for 3 days. After several washes in PB $0.1 \mathrm{M}$, slices were incubated with Streptavidin (Streptavidin AlexaFluor-555, $4 \mu \mathrm{g} / \mathrm{ml}$, Invitrogen) or species-matched secondary antibodies (anti-mouse AlexaFluor-647, $4 \mu \mathrm{g} / \mathrm{ml}$, Invitrogen) for $2 \mathrm{~h}$ at room temperature. Sections were counterstained with Dapi (1:10,000, 5 min, D3571 Invitrogen), washed in PB $0.1 \mathrm{M}$, and mounted onto gelatin-coated slides in Vectashieldmounting medium (Reactolab) to preserve fluorescent labelling. All immunostainings were performed in parallel on the same series of sections to minimize variability between groups.

Spinal cords were cleaned from their meninges before being divided into four parts corresponding to segments C1-C2, segments C3-C8, segments L1-L5, and a 4-mm piece containing the site of injury. The tissue was embedded in a gelatin-chicken albumin solution polymerized with $2.5 \%$ glutaraldehyde as previously described (Herzog and Brosamle 1997). The segments C1-C2 were cut in the coronal plane $(50 \mu \mathrm{m})$ to quantify the number of BDA-labelled CST fibres; horizontal sections $(50 \mu \mathrm{m})$ of segments C3-C8 were used to quantify the number of CST collaterals; coronal sections $(50 \mu \mathrm{m})$ of the lumbar spinal cords were used to assess completeness of the CST lesion (i.e. absence of BDA-stained CST axons) in injured mice; finally, cross-sections $(50 \mu \mathrm{m})$ were examined at the site of injury to measure the size and depth of the lesion. All sections were collected in PB $0.1 \mathrm{M}$, serially mounted onto superfrost slides (SuperFrostPlus, Menzel-Glaser, Germany) and processed using the semifree-floating technique (Herzog and Brosamle 1997). In brief, sections were washed in TBS-0.3\% Triton X-100 (TBS-TX, $50 \mathrm{mM}$ Tris, $0.875 \% \mathrm{NaCl}, 0.3 \%$ Triton $\mathrm{X}-100, \mathrm{pH}$ 8) before being incubated with avidin-peroxidase in TBS-TX (ABC elite, Vector Laboratories, Burlingame, CA, USA) for $1 \mathrm{~h}$ at room temperature. After an additional washing step in TBS-TX, a pre-incubation of $10 \mathrm{~min}$ in TBS-TX with $0.4 \%$ ammonium nickel sulphate (Sigma, St. Louis, MO, USA) was performed, followed by a second pre-incubation of $10 \mathrm{~min}$ in TBS-TX with $0.4 \%$ ammonium nickel sulphate and $0.015 \%$ 3,3-diaminobenzidine (DAB; Sigma, Buchs, Switzerland). The peroxidase reaction was started by addition of $0.004 \% \mathrm{H}_{2} \mathrm{O}_{2}$ and was stopped after $30 \mathrm{~min}$ by extensive washes in PB $0.1 \mathrm{M}$. Sections were air-dried and coverslipped with Eukitt (Kindler, Freiburg, Germany). Sections containing the injury site were counterstained with cresyl violet to facilitate lesion size measurement. Incompletely injured or overhemisected mice were eliminated from all the analyses.

Imaging and data analyses

Images of brain sections were acquired using a Leica TCS SP5 confocal inverted microscope or a Leica TCS SPE II confocal microscope (Leica Microsystems). Coordinates of the smHL cortex were defined by outlining the area including layer $\mathrm{V}$ pyramidal cell somata retrogradely labelled by DY injection at spinal cord level T8 (Neurolucida, MBF Biosciences). Mapping of GABAergic markers and PNNs was performed on 12 equally spaced $(240 \mu \mathrm{m}$ interval $)$ sections per animal covering the entire smHL as well as rostral and lateral regions, i.e. caudal motor forelimb (mFL) cortex and lateral sensory forelimb (sFL) cortex, respectively (rostrocaudal from Bregma: $+1.32 ;-1.16$ ). Three sampling areas, extending from the pia to the white matter, were defined on the left hemisphere on each coronal section with a mediolateral extent of $500 \mu \mathrm{m}$, positioned at $250 \mu \mathrm{m}$ intervals, starting $750 \mu \mathrm{m}$ lateral to the midline. Mediolateral coordinates for sampling area $1(0.75 ; 1.2)$; sampling area $2(1.45 ; 1.95)$; sampling area $3(2.2 ; 2.45)$. To count the number of cells positive for GAD67-GFP, $\mathrm{PV}$ and WFA, the sampling areas were subdivided in three regions of interest (ROI) according to the cortical layers identified by DAPI nuclear counterstaining (layers I-III, layer IV and layers V-VI). Cell counting was performed manually with Neurolucida software (MBF Biosciences) at a final magnification of $40 \times$. All data are given as number of cells per ROI at the following coordinates: $+1.08,+0.48,0$ (Bregma), -0.48 and -0.72 . Sampling areas 1 and 2 allowed quantifying cells in the smHL and $\mathrm{mFL}$, while sampling area 3 allowed quantifying cells in the sFL. Quantification of the expression level of GAD67-GFP, PV and WFA was 


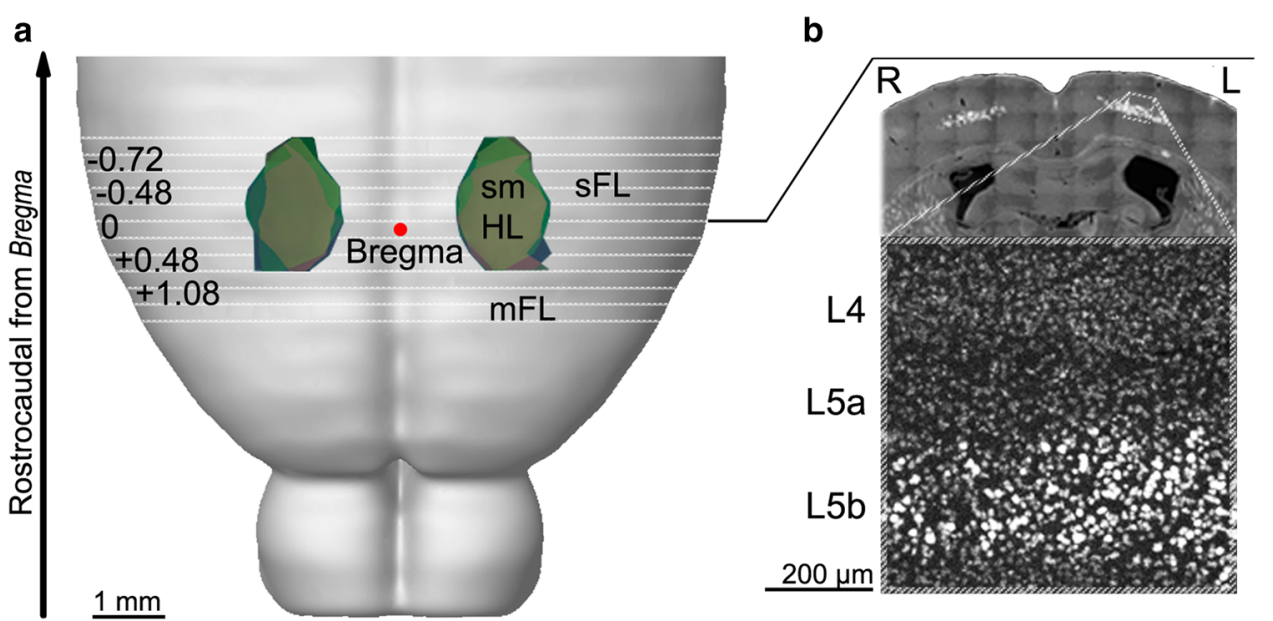

Fig. 1 Mapping of axotomized hindlimb-projecting corticospinal neurons in the mouse sensorimotor hindlimb (smHL) cortex. a Axotomized corticospinal neurons were retrogradely labelled by injection of the tracer Diamidine Yellow (DY) at the site of spinal cord injury (i.e. T8). Serial coronal sections of the forebrains were used to map the distribution of labelled cell bodies. The resulting areas are identified in three mice (blue, green and pink areas) and superimposed onto a brain template (http://wholebraincatalog.org). The

performed in layer $\mathrm{V}$ of the smHL and $\mathrm{mFL}$, where most of the changes in the number of cells expressing these markers were observed (see "Results"). Stacks were acquired in layer $\mathrm{V}$ at a final magnification of $40 \times$. All acquisition parameters for the same marker were identical between groups. To insure randomized, unbiased selection of the analysed cells, a regularly spaced grid was superimposed on every picture and all cells lying under the axes of the grid were analysed. The optical density (OD) and the body area were measured by outlining the cell body perimeter of every single cell using the LAS AF software (Leica microsystems, Mannheim, Germany). To minimize possible variability coming from the staining protocol, all values were normalized for the average intensity obtained from the control group. Collaterals in $\mathrm{C} 3-\mathrm{C} 8$ of intact and injured spinal cords were counted in complete series of adjacent, horizontal sections using the Neurolucida software (MBF Biosciences). The absolute number of collaterals was divided by the length of the analysed CST. To normalize for variation in tracing efficiency, these numbers were further divided by the total number of traced CST fibres counted at cervical level C1-C2 (average of 3 counts). The resulting index represents the number of cervical collateral per millimetre per labelled smHL CST fibres. The size of the SCI was estimated for all mice of groups 2, 6 and 7 by measuring the area of spared spinal cord tissue at the lesion epicentre.

All analyses were performed on a blinded basis. All values in the figures and in the text are presented as rostrocaudal $(+0.6 \mathrm{~mm} ;-1.4 \mathrm{~mm})$ and mediolateral (largest extension: 0.76 to $1.78 \mathrm{~mm}$ ) coordinates of the smHL are shown in reference to Bregma (red spot) and were consistent between mice. White lines represent the serial sections used for the analyses. $m F L$ motor forelimb, $s F L$ sensory forelimb. b Dapi staining (dark grey) was used to visualize the cortical layers. DY + cell bodies of axotomized pyramidal neurons (light grey) were located in layer $5 \mathrm{~b} . R$ right, $L$ left, $L 4$ layer $4, L 5 a$ layer 5 a, $L 5 b$ layer $5 \mathrm{~b}$

the mean \pm standard error of the mean. Statistical analyses were performed using two-way ANOVAs with the Bonferroni post hoc test or the Student's $t$ test.

\section{Results}

Mapping of the axotomized corticospinal neurons in the sensorimotor hindlimb cortex

To accurately map the region of the mouse sensorimotor cortex innervating the lumbar spinal cord, we retrogradely labelled the axotomized corticospinal neurons by injecting the tracer Diamidine Yellow (DY) at the site of injury (i.e. T8 dorsal hemisection). Serial coronal sections of the mouse forebrains were used to map the distribution of labelled cells and to define the coordinates of the sensorimotor hindlimb (smHL) cortex. The rostrocaudal $(+0.6 \mathrm{~mm} ;-1.4 \mathrm{~mm})$ and mediolateral (largest extension 0.76-1.78 mm) coordinates were set with reference to Bregma and were consistent between mice (Fig. 1a). All axotomized pyramidal neuron somata were found in layer $5 b$ (Fig. 1b). The regions located immediately rostral and lateral to the smHL cortex were defined as motor forelimb $(\mathrm{mFL})$ and sensory forelimb (sFL) areas, respectively (Ayling et al. 2009; Brown et al. 2009; Ghosh et al. 2012). The defined coordinates were used to select the sampling areas in which quantifications of GABAergic markers and PNNs were done. 

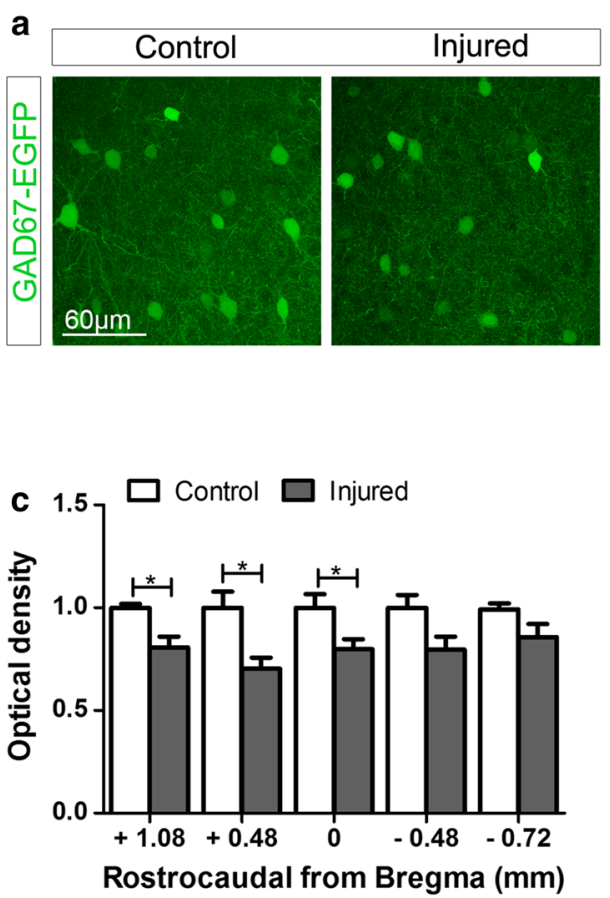

Fig. 2 Analysis of GAD67-GFP+ cells in cortical layers V-VI of control and injured mice. a Representative images showing GAD67GFP+ cells in layer V of control (left) and injured (right) mice at $+0.48 \mathrm{~mm}$ from Bregma. b The total number of GAD67-GFP+ cells was significantly decreased in the $\mathrm{mFL}$ of injured (grey bars) compared to control (white bars) mice. No differences were observed in the smHL cortex of the two groups. $\mathbf{c}$ Optical density measurement of single cells in layer $\mathrm{V}$ of the smHL and $\mathrm{mFL}$ cortex revealed that

Complex spatial changes of GABAergic markers occur in the sensory and motor cortex after SCI

We next studied the effects of a thoracic SCI on the spatial distribution of GAD67-GFP+, PV+ and WFAlabelled PNNs (WFA+ PNNs) throughout all cortical layers of the $\mathrm{mFL}$, smHL and sFL. In addition, we focused on layer $\mathrm{V}$ of the $\mathrm{mFL}$ and smHL cortical areas and measured the staining intensity (optical density of single cells) of the three markers and the cell body area of GAD67-GFP+ and PV+ cells (group 1, control, $n=4$; group 2, T8 injured, $n=7$ ). No changes could be detected in the total number of GAD67-GFP+ cells in any of the cortical layers of the smHL cortex (Fig. 2b and Online Resource 1), suggesting that no GABAergic cell death had occurred in the region where axotomized neurons were located. Interestingly however, the number of GFP+ interneurons in layers I-III and V-VI was significantly decreased in the $\mathrm{mFL}$ area $(+1.08$ rostrocaudal; 1.37 mediolateral; layers I-III, $p=0.027$, Online Resource 1; layers V-VI, $p=0.04$, Fig. 2b) and increased in the caudal sFL area $(-0.72$ rostrocaudal; 2.5 mediolateral; layers I-III, $p=0.037$; layers V-VI,
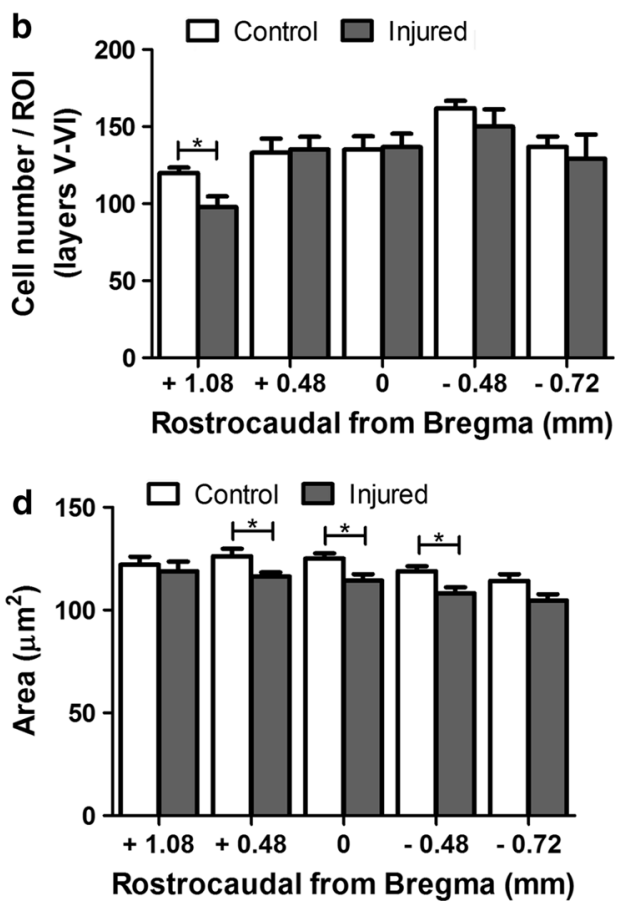

the expression of GAD67-GFP was significantly lower in injured (grey bars) compared to control (white bars) mice at the boundary between these two areas. d Measurement of GAD67-GFP+ cell body area revealed a small but significant atrophy of this cell population exclusively in the smHL cortex of injured (grey bars) compared to control (white bars) mice. No atrophy could be observed in the mFL cortex. * $p<0.05$. Student's $t$ test

$p=0.011$, Online Resource 1). These changes are unlikely to be related to death or birth of new GAD67+ cells, but rather suggest modulation of GAD67 expression after SCI. Regional changes in GAD67-GFP expression levels were confirmed by single cell body optical density measurement in layer $\mathrm{V}$ of the rostral smHL and mFL. In this regions, the intensity level of GAD67-GFP was significantly lower in injured compared to control mice $(+1.08 p=0.024 ;+0.48 p=0.01 ; 0$ $p=0.036$, Fig. 2a, c). In the mFL cortex, this decrease could largely be attributed to GABAergic PV-negative (GAD67-GFP+/PV-) cells, i.e. calretinin and/or somatostatin cells (Tamamaki et al. 2003), (Online Resource 2). In the smHL cortex, GABAergic interneurons that had downregulated PV following injury (see below) but could still be identified by their PNNs (GAD67-GFP+/WFA+/PV-) also contributed to this decrease (Online Resource 2). Finally, measurement of GAD67-GFP+ cell body area revealed a small but significant atrophy of this cell population exclusively in the smHL area, where axotomized CST neurons were located $(+0.48 p=0.027 ; 0 p=0.047 ;-0.48 p=0.033$, Fig. 2d). No atrophy could be observed in the mFL area 

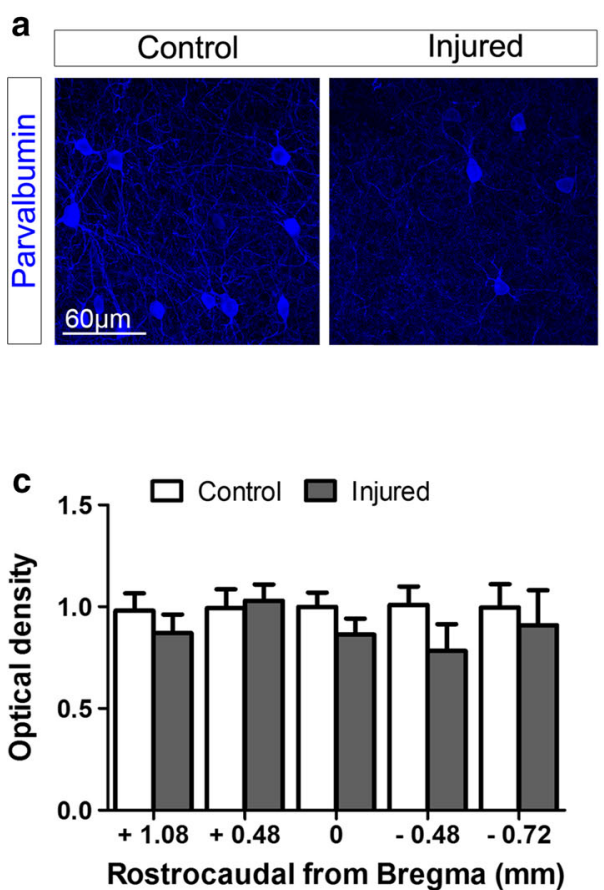

Fig. 3 Analysis of PV + cells in cortical layers V-VI of control and injured mice. a Representative images showing PV+ cells in layer $\mathrm{V}$ of control (left) and injured (right) mice at $+0.48 \mathrm{~mm}$ from Bregma. b The total number of PV+ cells was significantly decreased throughout the deeper layers (layers V-VI) of the smHL cortex of injured (grey bars) compared to control (white bars) mice. No differences were observed in the mFL cortex of the two groups.

indicating that the lower level of GAD67-GFP expression did not influence cell body area measurements.

We next focused our analysis on PV+ interneurons, which represent the primary source of cortical lateral inhibition on pyramidal neurons (Freund and Katona 2007). In the rodent cortex, PV+ cells are present in all layers except layer I and reach their peak density in the middle layers (van Brederode et al. 1991). Virtually all $\mathrm{PV}+$ interneurons in the cortex also express GAD67 (Tamamaki et al. 2003). A significant decrease in the number of PV+ cells was found throughout layers V-VI of the smHL cortex $(+0.48 p=0.033 ; 0 p=0.027 ;-0.48$ $p=0.024$, Fig. 3a, b). These changes were largely specific to the deeper layers, as no significant decrease was observed in more superficial layers of the same area or in other areas (Online Resource 3) and suggested a downregulation of the protein exclusively in a subpopulation of $\mathrm{PV}+$ cells. Indeed, measurements of single cell body optical density revealed that PV expression level remained stable in the population of detectable cells (Fig. 3a, c). Atrophy of PV+ cells was minimal and only reached statistical difference at $-0.48 \mathrm{~mm}$ caudal to Bregma $(p=0.03$, Fig. 3d). These data identify the presence of two subpopulations of PV cells in the deeper layers of the
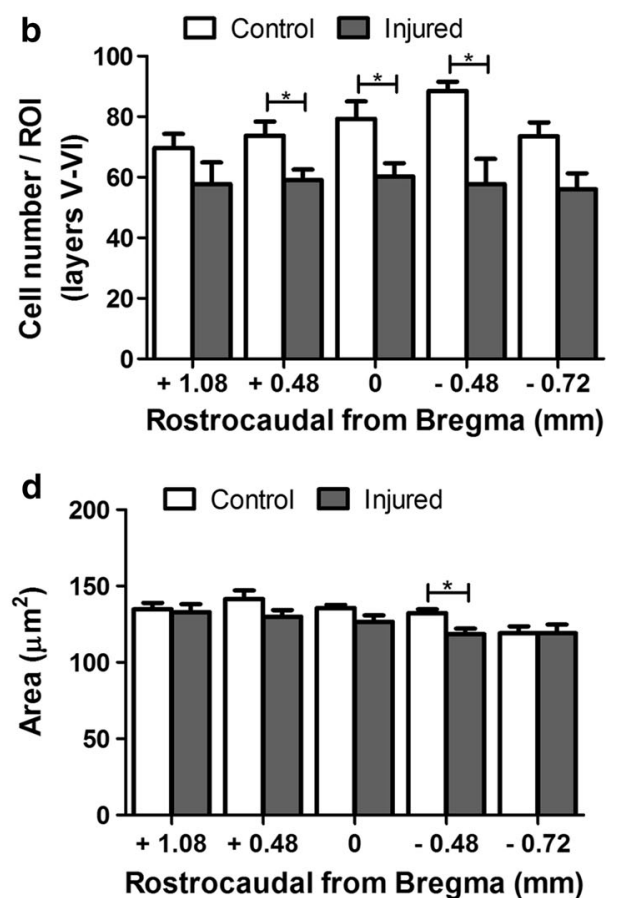

c Optical density measurement of single cells in layers $\mathrm{V}$ of the smHL and $\mathrm{mFL}$ cortex revealed that the expression levels of PV were comparable in the positive cell populations of control (white bars) and injured (grey bars) mice. d Atrophy of PV+ cells was minimal in injured mice (grey bars) and only reached statistical difference at $-0.48 \mathrm{~mm}$ caudal from Bregma compared to the control group (white bars). ${ }^{*} p<0.05$. Student's $t$ test

smHL cortex which differently responded to the injury: one where PV expression (and to some extent GAD67-GFP, see above) is persistently downregulated (cell undetectable by PV immunostaining) compared to control mice, and one that remains largely unaffected (cells detected by PV immunostaining).

Taken together these data indicate that SCI results in complex topographic and layer-specific changes in the expression of GABAergic markers in sensory and motor cortical areas. Moreover, they reveal that atrophy of inhibitory interneurons occurs in cortical layers where axotomized CST neurons are located.

SCI influences integrity of cortical PNNs at the boundary between mFL and smHL

To test for changes in CSPG GAG chain integrity, we focused our analysis on WFA+ PNNs (CSPG aggregates), which surround cortical PV cells. No changes in the total number of PNNs were observed in injured compared to control mice in any of the cortical areas and layers analysed (Fig. 4b and Online Resource 4). However, optical density measurement of single nets revealed a reduced WFA intensity staining at the 
Fig. 4 Analysis of PNN surrounded cells in cortical layers V-VI of control and injured mice. a Representative images showing WFA+ PNNs in layer $\mathrm{V}$ of control (left) and injured (right) mice at $+0.48 \mathrm{~mm}$ from Bregma. In this region, PNNs of injured mice appeared thinner and fainter compared to control mice. b No changes in the total number of WFA + PNNs were observed in injured (grey bars) compared to control (white bars). c Optical density measurement of single nets revealed a reduced WFA staining intensity at the boundary between $\mathrm{mFL}$ and smHL cortical areas. ${ }^{*} p<0.05$. Student's $t$ test
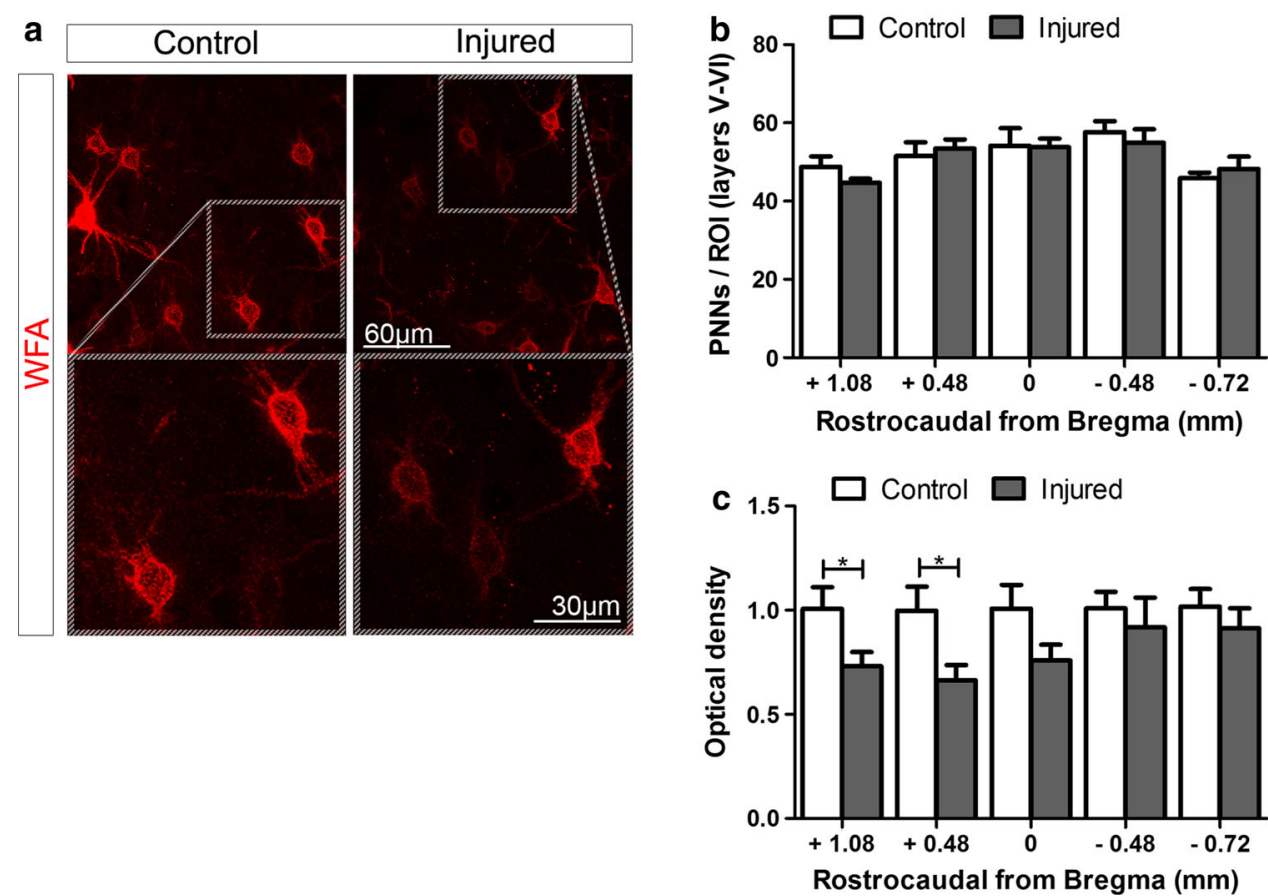

boundary between $\mathrm{mFL}$ and smHL cortical areas $(+1.08$ $p=0.046 ;+0.48 p=0.03$, Fig. $4 \mathrm{a}, \mathrm{c})$. In this region, PNNs appeared thinner and fainter in injured compared to control mice (Fig. 4a). To gain insight into the interplay between PV and integrity of PNNs, we measured the optical density of WFA + PNNs in individual $\mathrm{PV}+(\mathrm{GAD} 67-\mathrm{GFP}+/ \mathrm{WFA}+/ \mathrm{PV}+)$ and PV - (GAD67GFP+/WFA+/PV - ) cells. This analysis revealed that a reduction of WFA intensity occurred in both $\mathrm{PV}+$ and $\mathrm{PV}$ - subgroups suggesting that changes in cortical integrity of PNNs and PV expression after SCI are not directly related (Online Resource 5).

It is interesting to note that the reduction of PNN staining intensity occurred in a cortical region (at the boundary between the more rostral smHL and caudal mFL cortex) where axotomized CST neurons undergoing spontaneous anatomical and functional remodelling after SCI are located (Bareyre et al. 2004; Fouad et al. 2001; Ghosh et al. 2010). In particular, axotomized CST neurons located in the rostral smHL cortex form cervical axonal collaterals, which support recovery of motor functions after thoracic SCI (Fouad et al. 2001; Ghosh et al. 2010). In light of evidence showing restriction of structural and functional plasticity mediated by PNNs in the mature CNS, we hypothesized that changes in cortical PNN CSPGs integrity after SCI might be instrumental for CST remodelling in the spinal cord. We therefore tested if experimental widespread digestion of cortical CSPG GAG chains would have influenced spontaneous anatomical CST plasticity and recovery of motor functions.
We injected $\mathrm{ChABC}$ or the control enzyme Pase into the left smHL cortex of $\mathrm{C} 57 / \mathrm{B} 16$ mice in combination with (groups 6 and 7) or without a complete T8 CST transection (groups 3-5). At 3 days post-injection, the area of enzymatic digestion had a rostrocaudal extension of $2.709 \pm 0.125 \mathrm{~mm}$ starting at $+0.942 \pm 0.137 \mathrm{~mm}$ from Bregma, thus including the boundary between $\mathrm{mFL}$ and smHL and the smHL cortex. This area was almost completely devoid of PNNs (Fig. 5a). In the digested area, measurement of WFA-stained sections at 3, 7 and 14 days after ChABC treatment revealed a gradual reappearance of PNNs (Fig. 5a-c). The density of WFA + PNNs however remained below control levels at all time points (number of $\mathrm{WFA}+\mathrm{PNNs} / 100 \mu \mathrm{m}^{2}$ at day 3 after the injection: $1.91 \pm 0.26, p<0.001 ; 7: 4.86 \pm 0.37, p=0.03 ; 14$ : $4.77 \pm 0.49, p=0.03$, Fig. $5 b$ ), and was significantly different 3 days after injection compared to both longer time points (3vs. 7 days, $p<0.001 ; 3$ vs. 14 days, $p<0.01$ ).

Intracortical $\mathrm{ChABC}$ injection transiently exacerbates motor deficits

To address the effects of cortical CSPG GAG chains digestion on motor function recovery, mice of groups 4-7 were assessed using the Basso Mouse Scale (BMS) score and the horizontal grid walking test at different time points after injury. The BMS score evaluates over-ground locomotor activity in an open field. The two control unlesioned groups (groups 4 and 5) reached the highest score throughout the testing period (Fig. 6a) indicating that 
a
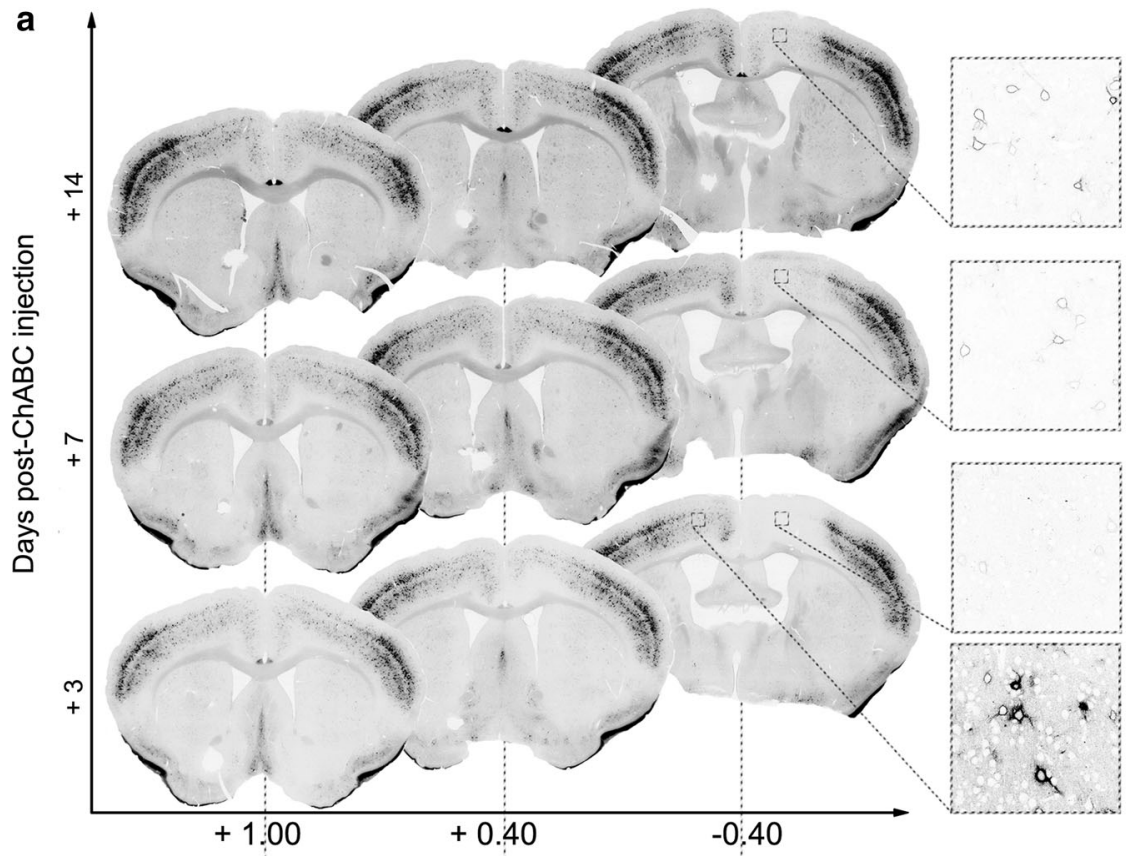

b
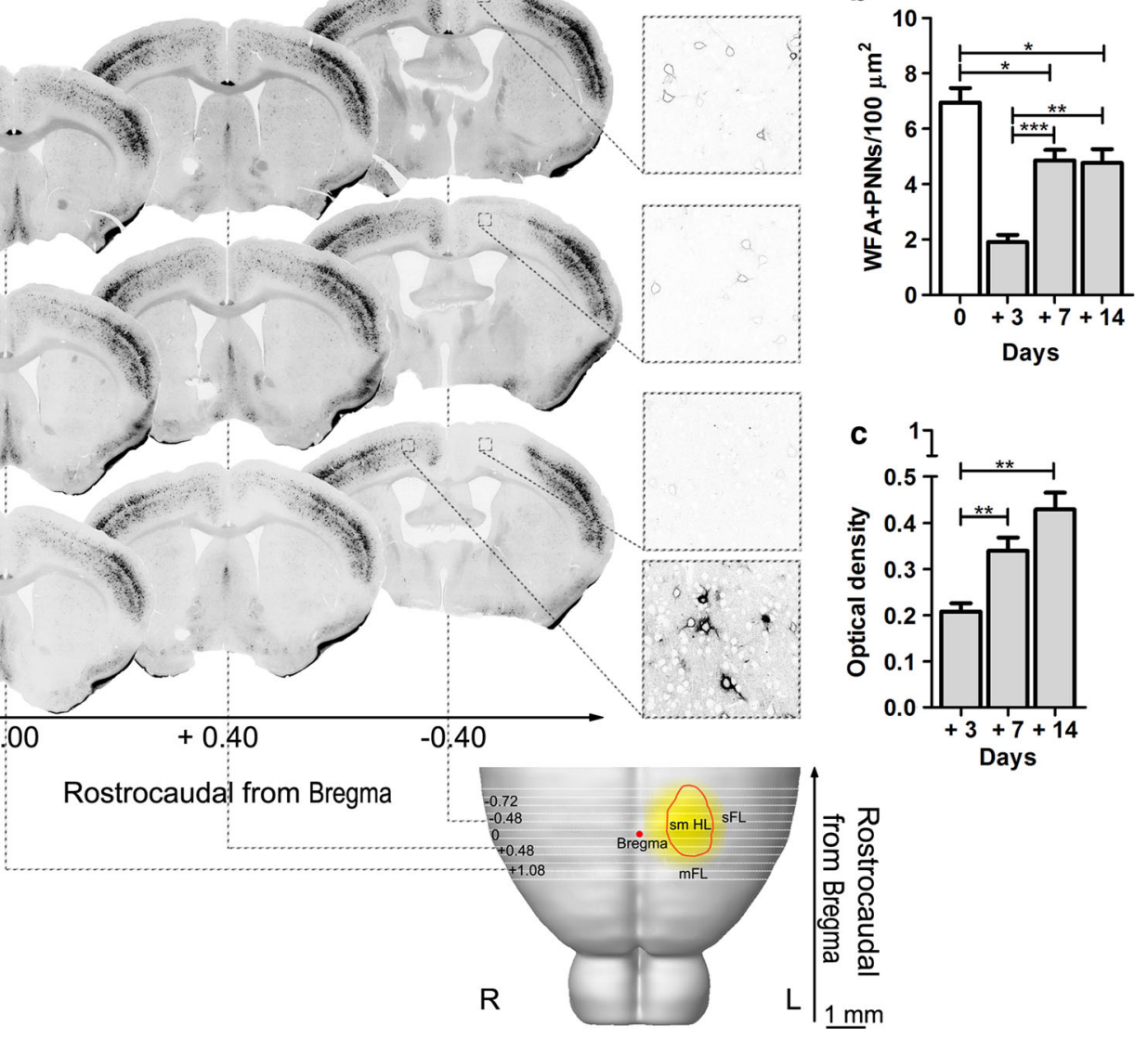

Fig. 5 Reconstruction of ChABC-digested area and gradual reappearance of PNNs at 3,7 and 14 days after ChABC injection. a The digested area (yellow) was superimposed onto a brain template (http:// wholebraincatalog.org). The orange circle outlines the smHL area. The area devoid of WFA staining had a rostrocaudal extension of $2.709 \pm 0.125 \mathrm{~mm}$ and included the boundary between $\mathrm{mFL}$ and smHL, and the smHL cortex. Magnifications show PNNs in the

neither ChABC nor Pase intracortical injection per se affected the gross locomotor ability of uninjured mice. During the 4 weeks post-injury, the locomotor rating scale of the injured groups 6 and 7 remained significantly lower than the control groups (group 4 and 5, respectively) and never recovered to control level. Importantly, the BMS scores were consistent between injured mice and comparable between the two groups, suggesting that locomotion and the extent of the lesion were similar in all mice.

The horizontal grid test examines the deficits in descending fine motor control and therefore represents a more specific test to assess CST integrity. Video recording allowed us to quantify the number of hindpaw slips (footfalls, Fig. 6b) on both sides (i.e. contralateral and ipsilateral to the injection). Digestion of CSPGs in the sensorimotor cortex of unlesioned mice did not affect CST-dependent descending motor control (Fig. 6c, d). All unlesioned mice of groups 4 and 5 (Pase and digested area (ipsilateral to the injection) and in the contralateral vehicle-treated hemicortex (only at 3 days post-injection). Note the gradual reappearance of PNNs at 7 and 14 days as thin and faint structures. b, c In the digested area, the density of WFA+ PNNs was below control levels (day 0) at all time points analysed and a gradual increase of WFA staining intensity could be observed. $* p<0.05$, ${ }^{* *} p<0.01,{ }^{* * *} p<0.001$. $R$ right, $L$ left. Student's $t$ test

ChABC injected, respectively) walked on the grid with ease, showing correct hindpaw placement. In contrast, mice of both injured groups 6 and 7 showed poor performance in the first 2 weeks after injury when compared with the respective control mice (Fig. 6c, d). Interestingly, stepping with the right hindpaw (opposite to the site of cortical injection) was more severely impaired in injured mice treated with $\mathrm{ChABC}$ (i.e. group 7), when compared with injured Pase-treated mice (i.e. group 6). The severity of this deficit reached the highest and significant levels at 3 and $7 \mathrm{dpi}$ (at $3 \mathrm{dpi} * * * p<0.001$; at 7 dpi $* * p<0.01$ two-way ANOVA with Bonferroni post hoc test), when cortical PNNs were fully digested, and returned to values comparable to injured Pase-treated mice at $14 \mathrm{dpi}$, when PNNs-CSPGs reappeared in the digested area (Figs. 5a, 6c). By 28 dpi, both injured groups had recovered fine motor function of the right hindpaw to control levels. 

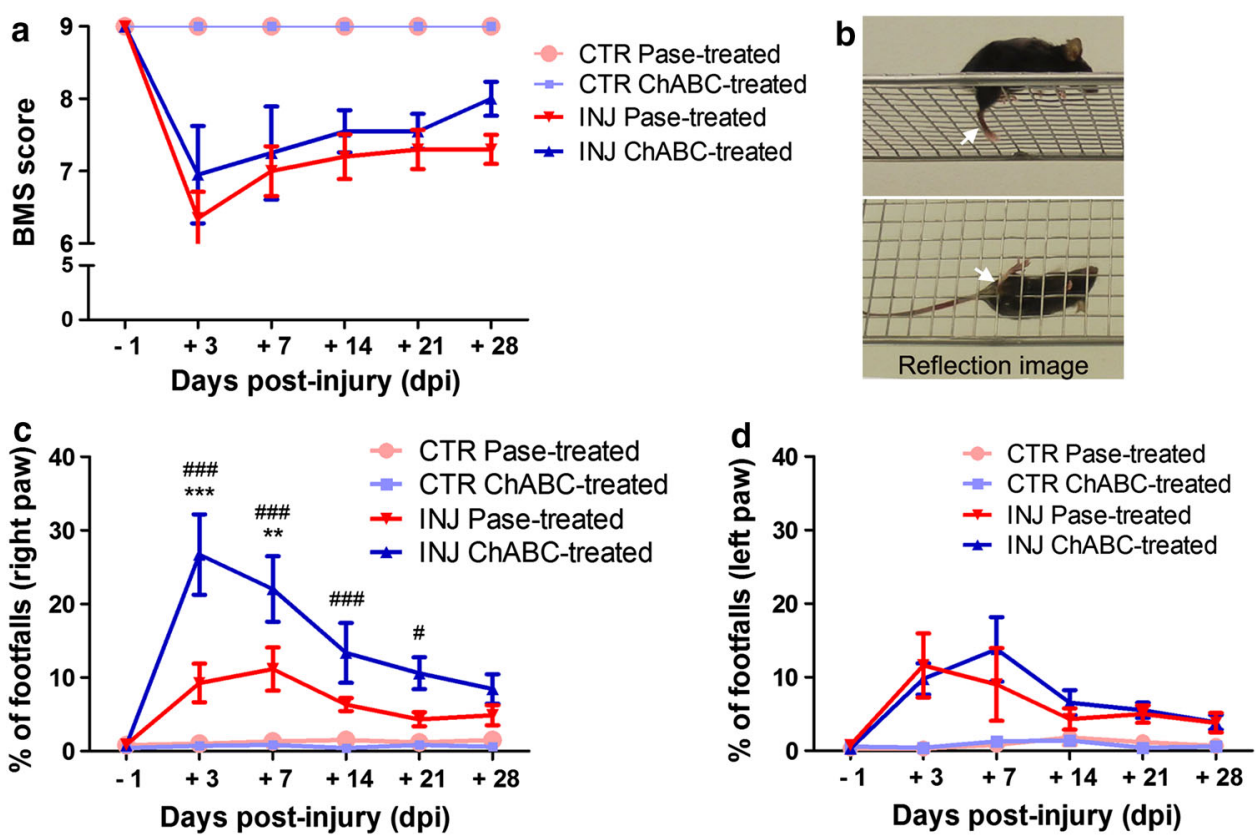

Fig. 6 Intracortical $\mathrm{ChABC}$ injection transiently exacerbates motor deficits. a Functional recovery of over-ground locomotion was assessed with the Basso Mouse Scale (BMS) score before ( -1 days) and after injury $(+3,7,14,21,28$ days). The two control unlesioned groups (groups 4, pink; group 5, light blue) reached the highest score throughout the testing period. The locomotor rating scale of the two injured groups (group 6, red; group 7, blue triangles) was always significantly lower than the control groups. No differences were detected between the scores of the injured groups at any time point. b Representative snapshot of a video recording showing a footfall (hindpaw slips) from the grid. The lower image is given by the reflection in a mirror positioned below the grid. White arrows indicate the slipping hindpaw. c Mice of both injured groups 6 (group 6, red) and 7 (group 7, blue) showed poorer performances in the first 2 weeks

All together these data indicate that cortical CSPG GAG chains digestion transiently exacerbates functional CSTassociated motor deficits after thoracic SCI.

Intracortical ChABC injection impairs the spontaneous intraspinal sprouting of axotomized CST neurons

Sprouting of the CST has been shown to occur spontaneously after SCI, leading to the formation of new intraspinal functional circuits (Bareyre et al. 2004) that participate in the functional reorganization of the sensorimotor cortex (Fouad et al. 2001; Ghosh et al. 2009). Thus, immediately after completion of behavioural testing ( $28 \mathrm{dpi}$ ), the CST originating in the left hemisphere was anterogradely traced with BDA in groups $4-7$, and the animals were euthanized 2 weeks later. The size of the SCI was estimated by measuring the area of spared spinal cord tissue at the centre of the lesion (Fig. 7a). No significant difference was detected between groups 6 and 7 (average spared spinal cord tissue in group 6: $0.88 \pm 0.05 \mathrm{~mm}^{2}$, in group 7: after injury compared to the respective control mice (groups 4, pink; group 5, light blue). Stepping with the right hindpaw (opposite to the site of cortical injection) was more severely impaired in mice treated with ChABC (group 7, blue), when compared to injured Pase-treated mice (group 6, red). The severity of this deficit reached the highest and significant levels at 3 and $7 \mathrm{dpi}$, when cortical PNNs were strongly digested (see Fig. 5a-c), and returned to values comparable to injured Pase-treated mice at $14 \mathrm{dpi}$, when PNNs reappeared in the digested area. $\mathbf{d}$ The time course of spontaneous recovery for the left hindpaw of injured ChABC-treated mice (group 7, blue) was comparable with the left and right hindlimbs of injured Pase-treated mice (group 6, red). Group $7 v s$. group 6: $* * p<0.01, * * * p<0.001$; group $7 v$ s. group 5: ${ }^{\#} p<0.05,{ }^{\# \#} p<0.001$, two-way ANOVA with Bonferroni post hoc test

$0.91 \pm 0.06 \mathrm{~mm}^{2}, \quad p=0.755$; percentage compared to intact spinal cord in group 6: $59.52 \%$, in group 7: $61.16 \%)$. In all mice of groups 6 and 7, the CST was completely transected as demonstrated by the absence of BDA-positive fibres in the lumbar enlargement caudal to the lesion (Fig. 7b). Large portions of the dorso-lateral and ventral funiculi were spared by the lesion (Fig. 7a). Cortical diffusion of BDA was comparable between all groups, with no tracer spreading into the deep white matter or subcortical structures. BDA+ cell bodies were found solely in the smHL cortex with no cells observed in the mFL cortex. No significant difference was observed in the number of BDA-labelled fibres in the four groups (crosssection at level $\mathrm{C} 1-2)$ indicating that neither ChABC nor Pase injections impaired BDA uptake or induced a loss of CST neurons. Collaterals were analysed in horizontal sections of the cervical (C3-C8) spinal cord (Fig. 7c, d). The number of collaterals from CST axons was significantly increased in the injured Pase-treated mice compared to control unlesioned mice (unlesioned Pase-treated mice, 
a

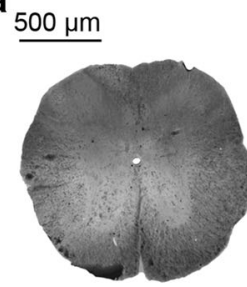

Control

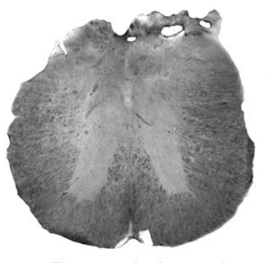

Pase-Injured

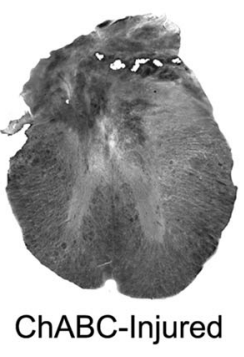

ChABC-Injured

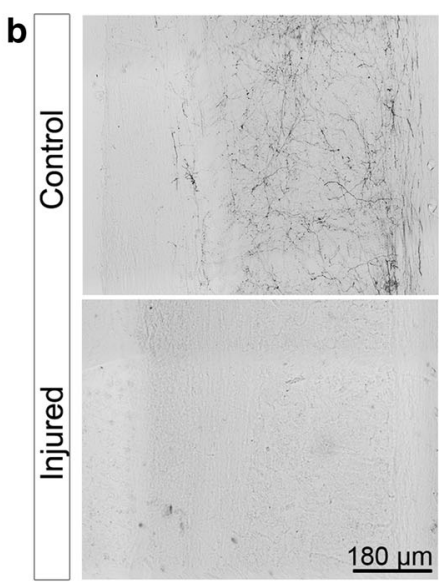

d

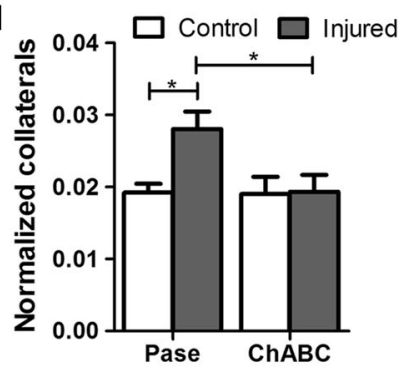

Fig. 7 Intracortical ChABC injection impairs spontaneous long-term intraspinal sprouting of axotomized CST neurons. a Representative images showing the area of spared spinal cord tissue in control mice (control) and at the centre of the lesion in injured Pase-treated (group 6) and injured ChABC-treated mice (group 7). No significant difference was detected between groups. b Representative images showing the absence of BDA-positive fibres in the lumbar enlargement caudal to the lesion in injured ChABC-treated (lower picture) compared to control ChABC-treated (upper picture) mice.

group 4, $p=0.015$; unlesioned ChABC-treated mice, group $5, p=0.021$ ). Surprisingly, in group 7 , which received a $\mathrm{SCI}$ and $\mathrm{ChABC}$ cortical injection, the number of cervical collaterals was significantly lower than in group $6(p=0.02)$ and not different from the two control unlesioned groups, indicating that digestion of cortical CSPG GAG chains abolished spontaneous long-term sprouting of axotomized CST neurons rostral to the site of injury.

\section{Discussion}

In this study, we showed that a thoracic SCI in mice is followed by specific spatial changes in the expression of GAD67 and PV in motor and sensory cortical areas, as well as by reduced WFA-stained PNNs at the boundary between the smHL and mFL cortical areas. Digestion of CSPG GAG chains over a larger sensorimotor cortical area by intracortical ChABC injection was used as a strategy to promote anatomical reorganization of the CST and motor c Representative images showing BDA+ collaterals in horizontal sections of the cervical (C3-C8) spinal cord of mice in groups 4 to 7 . White arrows indicate collaterals in Pase-treated mice (group 6). d The number of collaterals from CST axons was significantly increased in injured Pase-treated mice compared to control unlesioned mice of both groups. In group 7 (injured $\mathrm{ChABC}$-treated mice) the number of cervical collaterals was significantly lower than in group 6 and not different from the two control unlesioned groups. ${ }^{*} p<0.05$, Student's $t$ test

function recovery. Our results however showed that intracortical ChABC injection prevented CST sprouting rostral to the site of SCI and worsened motor control deficits, suggesting that these cortical changes must be discrete and tightly controlled to be of functional benefit.

Our results highlighted that a number of spatially restricted changes occurred in GABAergic circuits of the sensorimotor cortex after SCI. We detected an atrophy of layer $\mathrm{V}$ interneurons throughout the smHL, but not in the adjacent mFL cortex. The smHL contains the cell bodies of axotomized CST neurons, which undergo severe atrophy (Nielson et al. 2010; Carter et al. 2008; Tang et al. 2004; McBride et al. 1989; Ghosh et al. 2012) as a consequence of loss of trophic support (Tetzlaff et al. 1994; Giehl and Tetzlaff 1996; Kobayashi et al. 1997). The decreased metabolic activity of the axotomized pyramidal neurons onto which GAD67+ cells project might have locally impaired trophic support and triggered the observed atrophy of interneurons. Such a dependence of interneurons to pyramidal cells integrity is supported by the observation of 
a similar pattern of GABAergic neurons atrophy after projection neuron apoptosis (Al-Abdulla and Martin 2002).

Systematic cell number quantification and intensity measurement also revealed a decreased expression of GAD67 and PV in the sensorimotor cortex after SCI. The decrease of these activity-dependent GABAergic markers (Lau and Murthy 2012; Kinney et al. 2006) strongly supports the prevailing view that cortical disinhibition underlies experience-driven circuits remodelling. It is likely that these cortical changes were triggered by the transection of ascending sensory afferences, as suggested by Ghosh et al. (2009) and studies in the visual cortex showing that eye removal, TTX injection or monocular deprivation leads to similar observations (Hendry and Jones 1988; Sale et al. 2007). Interestingly, a similar decline of cortical GAD67 and PV expression has also been reported in various CNS pathologies, such as psychiatric disorders (Reynolds et al. 2004), Alzheimer's disease (Solodkin et al. 1996), epilepsy (Lau et al. 2000) as well as during cortical microstimulation-induced circuit remodelling (Benali et al. 2008). Under all these conditions, the decreased expression of those markers is believed to indicate a change of neuronal network activity. Interestingly, our work revealed that these changes occurred in discrete regions and/or layers of the sensorimotor cortex after SCI. Two weeks after SCI, downregulation of GAD67 expression was observed across the caudal $\mathrm{mFL}$ and rostral smHL cortex, whereas a reduced number of $\mathrm{PV}+$ cells was only detected in the deeper layers of the axotomized smHL cortex. This complex pattern of disinhibition of cortical circuits might support the profound remodelling occurring in the $\mathrm{mFL}$ and smHL cortex after SCI in rodents (Fouad et al. 2001; Ghosh et al. 2010, 2012). Interestingly, opposite changes (i.e. increased GAD67 expression) were observed in the intact caudal sFL, possibly aimed at confining the reorganization of cortical circuits to precise cortical sensorimotor areas (Benali et al. 2008).

In parallel to the interneuron atrophy and changes in activity-dependent GABAergic marker expression reported above, we observed a spatially localized reduction in the integrity of CSPG GAG chains associated with PNNs (revealed as significant reduction in the intensity of WFA staining). This reduction was more pronounced at the transition region between the $\mathrm{mFL}$ and smHL cortical areas, a region containing pyramidal neurons that spontaneously sprout into the cervical spinal cord after thoracic SCI (Fouad et al. 2001; Ghosh et al. 2010). Accumulating evidence support the existence of an interplay between experience-dependent plasticity and integrity of PNNs. PNNs appear at the end of the critical period for plasticity and persist in adulthood where they restrict functional plasticity of mature neuronal circuits (Kwok et al. 2011). Knocking out components essential for their assembly prolongs a juvenile state of plasticity into adulthood (Carulli et al. 2010). Enhanced expression of metalloproteinases (MMPs), that can degrade CSPGs forming PNNs, promotes experience-dependent cortical reorganization (Wang et al. 2008; Michaluk et al. 2011), and is observed together with reduced density of PNNs in cortical areas undergoing reorganization after stroke (Bidmon et al. 1998; Hobohm et al. 2005). In light of these data, our results suggested that changes in the integrity of cortical CSPG GAG chains, particularly in PNNs, might contribute to the promotion of motor circuit remodelling after SCI. To test if the reduction of cortical PNN CSPG integrity observed in the rostral smHL was instrumental to compensatory plasticity of the CST, we performed unilateral ChABC injection to digest their GAG chains over a larger area of the smHL cortex. Instead of promoting recovery, our results indicated that broad digestion of cortical CSPG GAG chains, revealed as the absence of WFA-stained PNNs, was detrimental to compensatory CST plasticity after SCI. This contrast with previous studies reporting that intraspinal or intrathecal delivery of ChABC after SCI promotes anatomical and functional repair of both descending motor (Barritt et al. 2006; Bradbury et al. 2002; Carter et al. 2008; Garcia-Alias et al. 2008, 2009; Fouad et al. 2005) and ascending sensory projections (Cafferty et al. 2008). A key difference between these previous studies and our study is the site of ChABC delivery. Thus, while ChABC activity at or around the site of SCI promotes repair, intracortical injection of this enzyme (our study) results in transient aggravation of behavioural deficits. We indeed observed rapid (i.e. at 3 and $7 \mathrm{dpi}$ ) and limbspecific worsening of motor function recovery, which eventually disappeared at longer time points (i.e. $28 \mathrm{dpi}$ ) when cortical PNNs reappeared in the digestion area. The early occurrence of these deficits suggests that ChABC-mediated digestion of PNN CSPGs disrupted rapid changes taking place in the sensorimotor cortex after SCI, such as reduction of intracortical inhibition and unmasking or reorganization of synapses which sustain motor function recovery (Jacobs and Donoghue 1991; Levy et al. 2002; Aguilar et al. 2010). It is possible that, by perturbing these rapid changes, ChABC treatment delays the formation and/or consolidation of new meaningful cortical circuits following injury. Impairment of motor function recovery after intraspinal delivery of ChABC in an animal model of SCI was also reported by Garcia-Alias et al. (2009). In this study, ChABC treatment induces worsening of motor tasks that were not actively trained after the injury. Interestingly, ChABC has a persistence of at least 10 days after a single injection in vivo (Lin et al. 2008), which roughly correspond to the timing of worsening of motor recovery 
that we observed in ChABC-treated animals. Afterwards, the replacement of newly synthesized glycans in PNNs might parallel or initiate compensatory mechanisms in the cortex to support spontaneous motor function recovery at longer time points (21 and $28 \mathrm{dpi}$ ). The nature of these compensatory mechanisms is likely to be diverse, including changes not only of neuronal circuitries but also of neuronal intrinsic properties. For example, a similar transient phenotype was recently reported for pyramidal cells excitability after downregulation of GAD67 in PV+ interneurons in juvenile mice, illustrating the exquisite capacity of cortical circuits to adapt to pathological situations (Lazarus et al. 2013).

Intracortical ChABC injection also blocked the spontaneous sprouting of axotomized CST fibres in the cervical spinal cord (Bareyre et al. 2004; Fouad et al. 2001; Ghosh et al. 2009). Modulation of the physiological properties of PNNs-surrounded $\mathrm{PV}+$ interneurons after ChABC treatment (Dityatev et al. 2007) might influence the early network remodelling induced by SCI and drive changes in cortical network activity, thereby influencing CST sprouting abilities (Salimi et al. 2008). However, changes of dendritic structural and functional plasticity mediated by diffused CSPGs cannot be ruled out (Orlando et al. 2012; de Vivo et al. 2013). CSPGs signalling through the protein tyrosine phosphatase sigma (Shen et al. 2009), the leukocyte common antigen-related phosphatase (Fisher et al. 2011) and the Nogo receptor family members NgR1 and NgR3 (Dickendesher et al. 2012) is known to affect plasticity. In addition, CSPGs may modulate signalling of growth promoting factors (e.g. Koprivica et al. 2005). Interestingly, despite the absence of CST sprouting in ChABC-treated mice, these animals eventually recovered to the level of the control Pase-treated group. This implies that a significant degree of functional recovery was achieved that did not involve CST sprouting in the cervical spinal cord. This spontaneous recovery most probably involves the reorganization of other parallel descending motor pathways (Raineteau and Schwab 2001).

Taken together our findings emphasize the existence of a fine and dynamic interplay between cortical GABAergic circuits, integrity of PNN CSPGs, and spontaneous plasticity of the adult-injured CST. Unlike previous observations in sensory cortical areas (Pizzorusso et al. 2002), intracortical ChABC delivery after SCI perturbs anatomical and functional CST reorganization, suggesting that spatial changes in cortical PNN integrity must be tightly controlled for meaningful reorganization of cortical motor output.

Acknowledgments This work was supported by the Stiftung für Forschung in Paraplegie, Zürich, [Grant Number: P91] and the Christopher and Dana Reeve Foundation. We are grateful to
Dr. A. Ghosh, Prof. M. E. Schwab, Dr. Urs Gerber, and Dr. J. Fawcett for valuable discussions.

Open Access This article is distributed under the terms of the Creative Commons Attribution License which permits any use, distribution, and reproduction in any medium, provided the original author(s) and the source are credited.

\section{References}

Aguilar J, Humanes-Valera D, Alonso-Calvino E, Yague JG, Moxon KA, Oliviero A, Foffani G (2010) Spinal cord injury immediately changes the state of the brain. J Neurosci 30(22):7528-7537

Al-Abdulla NA, Martin LJ (2002) Projection neurons and interneurons in the lateral geniculate nucleus undergo distinct forms of degeneration ranging from retrograde and transsynaptic apoptosis to transient atrophy after cortical ablation in rat. Neuroscience 115(1):7-14

Ayling OG, Harrison TC, Boyd JD, Goroshkov A, Murphy TH (2009) Automated light-based mapping of motor cortex by photoactivation of channelrhodopsin-2 transgenic mice. Nat Methods 6(3):219-224

Bareyre FM, Kerschensteiner M, Raineteau O, Mettenleiter TC, Weinmann O, Schwab ME (2004) The injured spinal cord spontaneously forms a new intraspinal circuit in adult rats. Nat Neurosci 7(3):269-277

Barritt AW, Davies M, Marchand F, Hartley R, Grist J, Yip P, McMahon SB, Bradbury EJ (2006) Chondroitinase ABC promotes sprouting of intact and injured spinal systems after spinal cord injury. J Neurosci 26(42):10856-10867

Basso DM, Fisher LC, Anderson AJ, Jakeman LB, McTigue DM, Popovich PG (2006) Basso Mouse Scale for locomotion detects differences in recovery after spinal cord injury in five common mouse strains. J Neurotrauma 23(5):635-659

Benali A, Weiler E, Benali Y, Dinse HR, Eysel UT (2008) Excitation and inhibition jointly regulate cortical reorganization in adult rats. J Neurosci 28(47):12284-12293

Beurdeley M, Spatazza J, Lee HH, Sugiyama S, Bernard C, Di Nardo AA, Hensch TK, Prochiantz A (2012) Otx2 binding to perineuronal nets persistently regulates plasticity in the mature visual cortex. J Neurosci 32(27):9429-9437

Bidmon HJ, Jancsik V, Schleicher A, Hagemann G, Witte OW, Woodhams P, Zilles K (1998) Structural alterations and changes in cytoskeletal proteins and proteoglycans after focal cortical ischemia. Neuroscience 82(2):397-420

Bradbury EJ, Moon LD, Popat RJ, King VR, Bennett GS, Patel PN, Fawcett JW, McMahon SB (2002) Chondroitinase ABC promotes functional recovery after spinal cord injury. Nature 416(6881):636-640

Brown CE, Aminoltejari K, Erb H, Winship IR, Murphy TH (2009) In vivo voltage-sensitive dye imaging in adult mice reveals that somatosensory maps lost to stroke are replaced over weeks by new structural and functional circuits with prolonged modes of activation within both the peri-infarct zone and distant sites. J Neurosci 29(6):1719-1734

Cafferty WB, Yang SH, Duffy PJ, Li S, Strittmatter SM (2007) Functional axonal regeneration through astrocytic scar genetically modified to digest chondroitin sulfate proteoglycans. J Neurosci 27(9):2176-2185

Cafferty WB, Bradbury EJ, Lidierth M, Jones M, Duffy PJ, Pezet S, McMahon SB (2008) Chondroitinase ABC-mediated plasticity of spinal sensory function. J Neurosci 28(46):11998-12009 
Caggiano AO, Zimber MP, Ganguly A, Blight AR, Gruskin EA (2005) Chondroitinase $\mathrm{ABCI}$ improves locomotion and bladder function following contusion injury of the rat spinal cord. J Neurotrauma 22(2):226-239

Carter LM, Starkey ML, Akrimi SF, Davies M, McMahon SB, Bradbury EJ (2008) The yellow fluorescent protein (YFP-H) mouse reveals neuroprotection as a novel mechanism underlying chondroitinase $\mathrm{ABC}$-mediated repair after spinal cord injury. J Neurosci 28(52):14107-14120

Carulli D, Pizzorusso T, Kwok JC, Putignano E, Poli A, Forostyak S, Andrews MR, Deepa SS, Glant TT, Fawcett JW (2010) Animals lacking link protein have attenuated perineuronal nets and persistent plasticity. Brain 133(Pt 8):2331-2347

Chau CH, Shum DK, Li H, Pei J, Lui YY, Wirthlin L, Chan YS, Xu XM (2004) Chondroitinase ABC enhances axonal regrowth through Schwann cell-seeded guidance channels after spinal cord injury. FASEB J 18(1):194-196

Courtine G, Song B, Roy RR, Zhong H, Herrmann JE, Ao Y, Qi J, Edgerton VR, Sofroniew MV (2008) Recovery of supraspinal control of stepping via indirect propriospinal relay connections after spinal cord injury. Nat Med 14(1):69-74

de Vivo L, Landi S, Panniello M, Baroncelli L, Chierzi S, Mariotti L, Spolidoro M, Pizzorusso T, Maffei L, Ratto GM (2013) Extracellular matrix inhibits structural and functional plasticity of dendritic spines in the adult visual cortex. Nat Commun 4:1484

Dickendesher TL, Baldwin KT, Mironova YA, Koriyama Y, Raiker SJ, Askew KL, Wood A, Geoffroy CG, Zheng B, Liepmann CD, Katagiri Y, Benowitz LI, Geller HM, Giger RJ (2012) NgR1 and $\mathrm{NgR} 3$ are receptors for chondroitin sulfate proteoglycans. Nat Neurosci 15(5):703-712

Dityatev A, Bruckner G, Dityateva G, Grosche J, Kleene R, Schachner M (2007) Activity-dependent formation and functions of chondroitin sulfate-rich extracellular matrix of perineuronal nets. Dev Neurobiol 67(5):570-588

Fisher D, Xing B, Dill J, Li H, Hoang HH, Zhao Z, Yang XL, Bachoo R, Cannon S, Longo FM, Sheng M, Silver J, Li S (2011) Leukocyte common antigen-related phosphatase is a functional receptor for chondroitin sulfate proteoglycan axon growth inhibitors. J Neurosci 31(40):14051-14066

Fouad K, Pedersen V, Schwab ME, Brosamle C (2001) Cervical sprouting of corticospinal fibers after thoracic spinal cord injury accompanies shifts in evoked motor responses. Curr Biol 11(22):1766-1770

Fouad K, Schnell L, Bunge MB, Schwab ME, Liebscher T, Pearse DD (2005) Combining Schwann cell bridges and olfactoryensheathing glia grafts with chondroitinase promotes locomotor recovery after complete transection of the spinal cord. J Neurosci 25(5):1169-1178

Freund TF, Katona I (2007) Perisomatic inhibition. Neuron 56(1):33-42

Garcia-Alias G, Lin R, Akrimi SF, Story D, Bradbury EJ, Fawcett JW (2008) Therapeutic time window for the application of chondroitinase ABC after spinal cord injury. Exp Neurol 210(2):331-338

Garcia-Alias G, Barkhuysen S, Buckle M, Fawcett JW (2009) Chondroitinase $\mathrm{ABC}$ treatment opens a window of opportunity for task-specific rehabilitation. Nat Neurosci 12(9):1145-1151

Ghosh A, Sydekum E, Haiss F, Peduzzi S, Zorner B, Schneider R, Baltes C, Rudin M, Weber B, Schwab ME (2009) Functional and anatomical reorganization of the sensory-motor cortex after incomplete spinal cord injury in adult rats. J Neurosci 29(39): 12210-12219

Ghosh A, Haiss F, Sydekum E, Schneider R, Gullo M, Wyss MT, Mueggler T, Baltes C, Rudin M, Weber B, Schwab ME (2010) Rewiring of hindlimb corticospinal neurons after spinal cord injury. Nat Neurosci 13(1):97-104

Ghosh A, Peduzzi S, Snyder M, Schneider R, Starkey M, Schwab ME (2012) Heterogeneous spine loss in layer 5 cortical neurons after spinal cord injury. Cereb Cortex 22(6):1309-1317
Giehl KM, Tetzlaff W (1996) BDNF and NT-3, but not NGF, prevent axotomy-induced death of rat corticospinal neurons in vivo. Eur J Neurosci 8(6):1167-1175

Harauzov A, Spolidoro M, DiCristo G, De Pasquale R, Cancedda L, Pizzorusso T, Viegi A, Berardi N, Maffei L (2010) Reducing intracortical inhibition in the adult visual cortex promotes ocular dominance plasticity. J Neurosci 30(1):361-371

Hendry SH, Jones EG (1988) Activity-dependent regulation of GABA expression in the visual cortex of adult monkeys. Neuron 1(8):701-712

Herzog A, Brosamle C (1997) 'Semifree-floating' treatment: a simple and fast method to process consecutive sections for immunohistochemistry and neuronal tracing. J Neurosci Methods 72(1):57-63

Hobohm C, Gunther A, Grosche J, Rossner S, Schneider D, Bruckner $\mathrm{G}$ (2005) Decomposition and long-lasting downregulation of extracellular matrix in perineuronal nets induced by focal cerebral ischemia in rats. J Neurosci Res 80(4):539-548

Jacobs KM, Donoghue JP (1991) Reshaping the cortical motor map by unmasking latent intracortical connections. Science 251(4996):944-947

Kinney JW, Davis CN, Tabarean I, Conti B, Bartfai T, Behrens MM (2006) A specific role for NR2A-containing NMDA receptors in the maintenance of parvalbumin and GAD67 immunoreactivity in cultured interneurons. J Neurosci 26(5):1604-1615

Kobayashi NR, Fan DP, Giehl KM, Bedard AM, Wiegand SJ, Tetzlaff W (1997) BDNF and NT-4/5 prevent atrophy of rat rubrospinal neurons after cervical axotomy, stimulate GAP-43 and Talpha1tubulin mRNA expression, and promote axonal regeneration. J Neurosci 17(24):9583-9595

Koprivica V, Cho KS, Park JB, Yiu G, Atwal J, Gore B, Kim JA, Lin E, Tessier-Lavigne M, Chen DF, He Z (2005) EGFR activation mediates inhibition of axon regeneration by myelin and chondroitin sulfate proteoglycans. Science 310(5745):106-110

Kwok JC, Dick G, Wang D, Fawcett JW (2011) Extracellular matrix and perineuronal nets in CNS repair. Dev Neurobiol 71(11):1073-1089

Lau CG, Murthy VN (2012) Activity-dependent regulation of inhibition via GAD67. J Neurosci 32(25):8521-8531

Lau D, Vega-Saenz de Miera EC, Contreras D, Ozaita A, Harvey M, Chow A, Noebels JL, Paylor R, Morgan JI, Leonard CS, Rudy B (2000) Impaired fast-spiking, suppressed cortical inhibition, and increased susceptibility to seizures in mice lacking $\mathrm{Kv} 3.2 \mathrm{~K}+$ channel proteins. J Neurosci 20(24):9071-9085

Lazarus MS, Krishnan K, Huang ZJ (2013) GAD67 Deficiency in parvalbumin interneurons produces deficits in inhibitory transmission and network disinhibition in mouse prefrontal cortex. Cereb Cortex [Epub ahead of print]

Levy LM, Ziemann U, Chen R, Cohen LG (2002) Rapid modulation of GABA in sensorimotor cortex induced by acute deafferentation. Ann Neurol 52(6):755-761

Lin R, Kwok JC, Crespo D, Fawcett JW (2008) Chondroitinase ABC has a long-lasting effect on chondroitin sulphate glycosaminoglycan content in the injured rat brain. $\mathbf{J}$ Neurochem 104(2):400-408

Makara JK, Katona I, Nyiri G, Nemeth B, Ledent C, Watanabe M, de Vente J, Freund TF, Hajos N (2007) Involvement of nitric oxide in depolarization-induced suppression of inhibition in hippocampal pyramidal cells during activation of cholinergic receptors. J Neurosci 27(38):10211-10222

Massey JM, Hubscher CH, Wagoner MR, Decker JA, Amps J, Silver J, Onifer SM (2006) Chondroitinase ABC digestion of the perineuronal net promotes functional collateral sprouting in the cuneate nucleus after cervical spinal cord injury. J Neurosci 26(16):4406-4414

McBride RL, Feringa ER, Garver MK, Williams JK Jr (1989) Prelabeled red nucleus and sensorimotor cortex neurons of the rat survive 10 and 20 weeks after spinal cord transection. J Neuropathol Exp Neurol 48(5):568-576 
Michaluk P, Wawrzyniak M, Alot P, Szczot M, Wyrembek P, Mercik K, Medvedev N, Wilczek E, De Roo M, Zuschratter W, Muller D, Wilczynski GM, Mozrzymas JW, Stewart MG, Kaczmarek L, Wlodarczyk J (2011) Influence of matrix metalloproteinase MMP-9 on dendritic spine morphology. J Cell Sci 124(Pt 19):3369-3380

Moon LD, Asher RA, Rhodes KE, Fawcett JW (2001) Regeneration of CNS axons back to their target following treatment of adult rat brain with chondroitinase ABC. Nat Neurosci 4(5):465-466

Nielson JL, Sears-Kraxberger I, Strong MK, Wong JK, Willenberg R, Steward O (2010) Unexpected survival of neurons of origin of the pyramidal tract after spinal cord injury. J Neurosci 30(34):11516-11528

Orlando C, Ster J, Gerber U, Fawcett JW, Raineteau O (2012) Perisynaptic chondroitin sulfate proteoglycans restrict structural plasticity in an integrin-dependent manner. $\mathrm{J}$ Neurosci 32(50): 18009-18017

Oudega M, Perez MA (2012) Corticospinal reorganization after spinal cord injury. J Physiol 590(Pt 16):3647-3663

Pizzorusso T, Medini P, Berardi N, Chierzi S, Fawcett JW, Maffei L (2002) Reactivation of ocular dominance plasticity in the adult visual cortex. Science 298(5596):1248-1251

Raineteau O, Schwab ME (2001) Plasticity of motor systems after incomplete spinal cord injury. Nat Rev Neurosci 2(4):263-273

Reynolds GP, Abdul-Monim Z, Neill JC, Zhang ZJ (2004) Calcium binding protein markers of GABA deficits in schizophreniapostmortem studies and animal models. Neurotox Res 6(1):57-61

Sale A, Maya Vetencourt JF, Medini P, Cenni MC, Baroncelli L, De Pasquale R, Maffei L (2007) Environmental enrichment in adulthood promotes amblyopia recovery through a reduction of intracortical inhibition. Nat Neurosci 10(6):679-681

Salimi I, Friel KM, Martin JH (2008) Pyramidal tract stimulation restores normal corticospinal tract connections and visuomotor skill after early postnatal motor cortex activity blockade. J Neurosci 28(29):7426-7434

Shen Y, Tenney AP, Busch SA, Horn KP, Cuascut FX, Liu K, He Z, Silver J, Flanagan JG (2009) PTPsigma is a receptor for chondroitin sulfate proteoglycan, an inhibitor of neural regeneration. Science 326(5952):592-596
Solodkin A, Veldhuizen SD, Van Hoesen GW (1996) Contingent vulnerability of entorhinal parvalbumin-containing neurons in Alzheimer's disease. J Neurosci 16(10):3311-3321

Starkey ML, Bartus K, Barritt AW, Bradbury EJ (2012) Chondroitinase $\mathrm{ABC}$ promotes compensatory sprouting of the intact corticospinal tract and recovery of forelimb function following unilateral pyramidotomy in adult mice. Eur J Neurosci 36(12):3665-3678

Tamamaki N, Yanagawa Y, Tomioka R, Miyazaki J, Obata K, Kaneko $\mathrm{T}$ (2003) Green fluorescent protein expression and colocalization with calretinin, parvalbumin, and somatostatin in the GAD67-GFP knock-in mouse. J Comp Neurol 467(1):60-79

Tang XQ, Wang Y, Huang ZH, Han JS, Wan Y (2004) Adenovirusmediated delivery of GDNF ameliorates corticospinal neuronal atrophy and motor function deficits in rats with spinal cord injury. NeuroReport 15(3):425-429

Tester NJ, Howland DR (2008) Chondroitinase ABC improves basic and skilled locomotion in spinal cord injured cats. Exp Neurol 209(2):483-496

Tetzlaff W, Kobayashi NR, Giehl KM, Tsui BJ, Cassar SL, Bedard AM (1994) Response of rubrospinal and corticospinal neurons to injury and neurotrophins. Prog Brain Res 103:271-286

Tom VJ, Kadakia R, Santi L, Houle JD (2009) Administration of chondroitinase $\mathrm{ABC}$ rostral or caudal to a spinal cord injury site promotes anatomical but not functional plasticity. J Neurotrauma 26(12):2323-2333

van Brederode JF, Helliesen MK, Hendrickson AE (1991) Distribution of the calcium-binding proteins parvalbumin and calbindinD28k in the sensorimotor cortex of the rat. Neuroscience 44(1):157-171

Wang XB, Bozdagi O, Nikitczuk JS, Zhai ZW, Zhou Q, Huntley GW (2008) Extracellular proteolysis by matrix metalloproteinase-9 drives dendritic spine enlargement and long-term potentiation coordinately. Proc Natl Acad Sci USA 105(49):19520-19525

Weidner N, Ner A, Salimi N, Tuszynski MH (2001) Spontaneous corticospinal axonal plasticity and functional recovery after adult central nervous system injury. Proc Natl Acad Sci USA 98(6):3513-3518 